\title{
Coronatine inhibits stomatal closure and delays hypersensitive response cell death induced by nonhost bacterial pathogens
}

Pseudomonas syringae is the most widespread bacterial pathogen in plants. Several strains of $P$. syringae produce a phytotoxin, coronatine (COR), which acts as a jasmonic acid mimic and inhibits plant defense responses and contributes to disease symptom development. In this study, we found that COR inhibits early defense responses during nonhost disease resistance. Stomatal closure induced by a nonhost pathogen, $P$. syringae pv. tabaci, was disrupted by COR in tomato epidermal peels. In addition, nonhost HR cell death triggered by $P$. syringae pv. tabaci on tomato was remarkably delayed when COR was supplemented along with $P$. syringae pv. tabaci inoculation. Using isochorismate synthase (ICS)-silenced tomato plants and transcript profiles of genes in SA- and JA-related defense pathways, we show that COR suppresses SA-mediated defense during nonhost resistance. 
1 Coronatine inhibits stomatal closure and delays hypersensitive response cell death induced

2 by nonhost bacterial pathogens

3

4 Seonghee Lee $^{1}$, Yasuhiro Ishiga ${ }^{1}$, Kristen Clermont ${ }^{2}$ and Kirankumar S. Mysore ${ }^{1^{*}}$

5

$6 \quad{ }^{1}$ The Samuel Roberts Noble Foundation, Plant Biology, Ardmore, Oklahoma

$7 \quad{ }^{2}$ Virginia Tech, Department of Biological Sciences, Blacksburg, VA

8 *corresponding author: Kirankumar S. Mysore

Abstracts

11

Pseudomonas syringae is the most widespread bacterial pathogen in plants. Several strains of $P$.

13 syringae produce a phytotoxin, coronatine (COR), which acts as a jasmonic acid mimic and 14 inhibits plant defense responses and contributes to disease symptom development. In this study, 15 we found that COR inhibits early defense responses during nonhost disease resistance. Stomatal 16 closure induced by a nonhost pathogen, $P$. syringae pv. tabaci, was disrupted by COR in tomato 17 epidermal peels. In addition, nonhost HR cell death triggered by P. syringae pv. tabaci on tomato 18 was remarkably delayed when COR was supplemented along with $P$. syringae pv. tabaci 19 inoculation. Using isochorismate synthase (ICS)-silenced tomato plants and transcript profiles of 20 genes in SA- and JA-related defense pathways, we show that COR suppresses SA-mediated 21 defense during nonhost resistance. 


\section{Introduction}

Plants possess a natural innate immune system that efficiently detects potential pathogens. The initial stage of this defense system is based on the perception of pathogen- or microbe-associated molecular patterns (PAMPs or MAMPs) through pattern recognition receptors present at the plant cell surface (Boller \& Felix, 2009). Recent studies suggest that plant stomata can play an active role as part of the plant innate immune system in restricting bacterial invasion (Melotto et al, 2008; Melotto et al, 2006). Perception of multiple bacterial PAMPs, including flagellin, lipopolysaccharide (LPS) and elongation factor $\mathrm{Tu}(\mathrm{EF}-\mathrm{Tu})$, induced closure of stomata in epidermal peels of Arabidopsis leaves (Melotto et al, 2006). Moreover, a significant induction of stomatal closure was observed within the first hour of contact with both host and nonhost bacterial pathogens (Melotto et al, 2008). However, bacterial pathogens have evolved to acquire specific virulence factors such as coronatine (COR) to overcome PAMP-triggered immunity (PTI) and stomata-based defense (Underwood et al, 2007). For example, the virulent pathogen $P$. syringae pv. tomato DC3000 produces COR three hours after infection in the apoplast and on the plant surface to reopen closed stomata, thus allowing more bacteria to enter (Melotto et al, 2008; Melotto et al, 2006; Underwood et al, 2007). In addition, COR enhances bacterial multiplication in the apoplast and the formation of necrotic lesions (cell death) surrounded by chlorotic halos, thus promoting systemic susceptibility (Bender, 1999; Cui et al, 2005; Preston et al, 2001). Chlorosis associated with disease caused by several pathovars of $P$. syringae has been attributed mainly to the phytotoxin COR (Bender et al, 1987; Zhao et al, 2003).

COR consists of the polyketide coronafacic acid (CFA) (Brooks et al, 2005) and coronamic acid (CMA), a cyclized derivative of isoleucine (E. Mitchell, 1985). COR has 
47 structural and functional similarity to jasmonates and jasmonic acid-isoleucine (JA-Ile) (Katsir et 48 al, 2008; Uppalapati et al, 2005; Weiler et al, 1994). COR contributes to the virulence of $P$.

49

50

51

52

53

54 syringae pv. tomato DC3000 in Arabidopsis, tomato, collards (Brassica oleracea) and turnip (Brooks et al, 2004; Zhao et al, 2003). By mimicking jasmonates, COR stimulates the JA pathway in Arabidopsis and tomato, and thereby functions to suppress the SA pathway and/or closure of stomata, thus allowing bacteria to reach higher densities in planta (Melotto et al, 2006; Uppalapati et al, 2005; Zhao et al, 2003). In a recent study, Zheng et al., (Zheng et al, 2012) reported that COR disrupts the accumulation of the important plant defense hormone salicylic acid (SA) for stomatal reopening and bacterial propagation in both local and systemic tissues of Arabidopsis. However, it is not clear whether COR is also involved in promoting entry of nonhost bacterial pathogens via stomata and nonhost bacterial growth at the initial stage of infection.

P. syringae pv. tabaci is the causal agent for the wild fire disease in tobacco (F. \& Durbin, 1980). This pathogen does not produce COR and is unable to infect nonhost plant species such as tomato. It has been noted that most of the stomata in epidermal peels of tomato remained closed after three hours incubation with nonhost pathogen $P$. syringae pv. tabaci, while virulent pathogen $P$. syringae pv. tomato DC3000 producing COR is able to reopen stomata after three hours treatment in tomato epidermal peels (Melotto et al, 2006). In the current study, we examined how COR can affect the early defense responses including stomatal defense and nonhost HR cell death by a nonhost pathogen in tomato. In addition, we determined the expression of defense genes related to SA and JA pathways after treatment of host or nonhost pathogens along with COR. Our findings from this study clearly show that COR confers the 
virulence activity to suppress early plant defense systems against nonhost bacterial pathogens in tomato.

\section{Materials and Methods}

\section{Plant and pathogen materials}

Tomato (Solanum lycopersicum cv. Glamour) plants were grown on $10 \mathrm{~cm}$ diameter round pots containing potting soil (BM7) (Berger Co., Quebec, Canada) and maintained in the greenhouse under a 14-hour light/10-hour dark photoperiod at $23 \pm 2^{\circ} \mathrm{C}$. Four-week-old tomato plants were used for the experiments. P. syringae pv. tomato DC3000 and P. syringae pv. tomato T1 were used as virulence bacterial pathogens (host pathogens), and $P$. syringae pv. tabaci and $P$. syringae pv. phaseolicola were used as nonhost bacterial pathogens on tomato.

These host and nonhost bacterial pathogens were grown overnight at $28^{\circ} \mathrm{C}$ in King's $\mathrm{B}$ (KB) medium [(10g Proteose pepton \#2 (BD Difco, New Jersey, USA); 1.5g anhydrous K2HPO4; $15 \mathrm{~g}$ glycerol; $5 \mathrm{~mL}$ MgSO4 (1M sterile)] containing appropriate antibiotics (kanamycin $25 \mathrm{mg} / \mathrm{ml}$ and rifamycin $50 \mathrm{mg} / \mathrm{ml}$ ). After the overnight culture, bacterial cells were centrifuged at 5,000 rpm for $10 \mathrm{~min}$, and the cell pellet was resuspended in $10 \mathrm{ml}$ of sterile distilled water. The concentration of bacteria in the culture suspension was measured in a spectrophotometer (the optical density at OD $600 \mathrm{~nm}$ ) and diluted to appropriate concentrations for inoculations. 
91 Bacterial suspensions $\left(3 \times 10^{7} \mathrm{cfu} / \mathrm{ml}\right)$ were prepared in sterile distilled water containing $0.025 \%$

92 Silwet L-77 (OSI Specialties Inc., Danbury, CT, USA) and sprayed on tomato plants. The 93 inoculated plants were then incubated in growth chambers at 90 to $100 \% \mathrm{RH}$ for the first $24 \mathrm{hr}$.

94 The inoculated plants were observed at 7 dpi for symptom development. Bacterial growth in 95 leaves was measured by determining the internal bacterial population. Prior to sampling, leaves 96 were surface-sterilized with $15 \% \mathrm{H}_{2} \mathrm{O}_{2}$ for 3 min to eliminate epiphytic bacteria and then washed 97 with sterile distilled water. The leaves were then homogenized in sterile distilled water, and serial dilutions were plated onto KB medium containing antibiotics (kanamycin, 25mg/ml). The bacterial population at 0 dpi was estimated from leaves harvested $1 \mathrm{hr}$ post inoculation. Bacterial growth patterns at 0,1 and 3 dpi were evaluated in two independent experiments (four leaf samples per each experiment).

\section{Stomata assay}

104 The bacterial culture of $P$. syringae pv. tabaci was centrifuged and resuspended in distilled water at a concentration of $5 \times 10^{4} \mathrm{CFU} / \mathrm{ml}$. For stomatal closure assay, the tomato epidermal peel was prepared as described (Melotto et al, 2006). Epidermis of tomato leaves were peeled off and immediately floated on stomata opening buffer (10 mM MES-KOH, $30 \mathrm{mM} \mathrm{KCl,} \mathrm{pH6.3).} \mathrm{After}$ confirming stomata opening under the microscope, the epidermal peels were treated with $P$. syringae pv. tabaci with or without COR (100 ng/ml; obtained from C. Bender, Oklahoma State University). Approximately 100 random stomatal apertures were measured per each treatment, and three samples were collected from each experiment. 


\section{Inhibition of nonhost HR cell death by COR and bacterial growth determination}

115 To determine if COR inhibits nonhost HR cell death, two nonhost bacterial pathogens, $P$. 116 syringae pv. tabaci and $P$. syringae pv. phaseolicola were used for this experiment in tomato. 117 Bacterial cultures grown in $\mathrm{KB}$ medium overnight at $28^{\circ} \mathrm{C}$ were centrifuged (3,500 rpm, $\left.10 \mathrm{~min}\right)$ 118 and resuspended in MES buffer (MES $10 \mathrm{mM}, \mathrm{pH}$ 6.5). The bacterial suspension was infiltrated 119 into fully expanded tomato leaf using a $1.5 \mathrm{ml}$ needleless syringe for examining bacterial growth 120 and nonhost HR cell death. Three different concentrations (100, 200 and $300 \mathrm{ng} / \mathrm{ml})$ of COR 121 were tested to determine COR toxicity in tomatao leaves. Both 200 and $300 \mathrm{ng} / \mathrm{ml}$ showed visible cell death and chlorosis symptoms. The concentration of $100 \mathrm{ng} / \mathrm{ml}$ of COR was added to bacterial suspension $\left(10^{4} \mathrm{CFU} / \mathrm{ml}\right)$ to determine the inhibition of HR cell death. Infiltrated leaves were inspected for HR cell death after 24-hour and 48-hour inoculation. Tomato plants silenced in isochorismate synthase accumulation by RNAi (ICS-RNAi) (Uppalapati et al, 2007) were also used to evaluate if COR inhibit SA accumulation and suppress HR cell death. To determine whether the bacterial growth is promoted by COR, a low concentration of $P$. syringae pv. tabaci $\left(2 \times 10^{2} \mathrm{CFU} / \mathrm{ml}\right)$ was inoculated with or without COR. The bacterial population in the apoplast was examined at zero, one and three days after inoculation.

The detection of $\mathrm{H}_{2} \mathrm{O}_{2}$ in leaf tissues was done by 3,3'-diaminobenzidine (DAB) staining. $\mathrm{H}_{2} \mathrm{O}_{2}$ reacts with DAB to form a reddish-brown stain. $P$. syringae pv. tomato DC3000 and $P$. syringae pv. tabaci were infiltrated into one side of the tomato leaf with or without COR (100 ng/ml; obtained from C. Bender, Oklahoma State University) (Li et al, 2005; Zheng et al, 2012). The DAB staining procedure was followed as described (ojas et al, 2012). 


\section{RNA isolation and quantitative real-time RCR}

Total RNA was purified from tomato leaves infiltrated with water (mock control), COR, nonhost pathogen P. syringae pv. tabaci (Psta), Psta with COR, or host pathogen P. syringae pv. tomato T1 (Pst T1). Total RNA was extracted using TRIzol (Invitrogen), and two treated or inoculated leaves were pooled to represent one biological replicate. Total RNA was treated with DNase I (Invitrogen), and $1 \mu \mathrm{g}$ RNA was used to generate cDNA using Superscript III reverse transcriptase (Invitrogen) and oligo $\mathrm{d}(\mathrm{T}) 15-20$ primers. The cDNA $(1: 20)$ was then used for qRT-PCR using Power SYBR Green PCR master mix (Applied Biosystems, Foster City, CA, USA). Primers specific for tublin 4 was used to normalize small differences in template amounts. To determining COR-mediated inhibition of SA and JA hormonal pathway, real-time quantitative PCR was performed with primers shown in Table 1. Average Cycle Threshold (CT) values calculated using Sequence Detection Systems (version 2.2.2; Applied Biosystems) from duplicate samples were used to determine the fold expression relative to controls. All qRT-PCR were performed using ABI PRISM 7700 Sequence Detection System (Applied Biosystems, CA, USA) and calculation was made according to the company manual (User Bulletin \#2).

\section{Results and Discussion}

Pseudomonas syringae pv. tabaci inoculation on tomato induces rapid closure of stomata and nonhost HR

The bacterial pathogen $P$. syringae pv. tomato DC3000 causes bacterial speck disease on a host plant, tomato. Five days after spray inoculation of $P$. syringae pv. tomato DC3000, a number of 
160 bacterial leaf spots at infection sites were observed in tomato. In contrast, nonhost bacterial 161 pathogen $P$. syringae pv. tabaci that is the causal agent for wildfire leaf disease in tobacco is 162 unable to infect tomato (Supplemental Fig. S1A). At the initial infection process, bacterial 163 pathogens produce virulence effectors to disrupt early plant defense systems such as the 164 stomata-based immunity $(2,3)$ and the HR cell death at the site of infection (4). Stomata are the 165 active barriers in limiting bacterial entry into apoplast. Several recent studies showed that 166 stomatal closure induced by bacterial pathogens or bacterial PAMPs is a common plant defense 167 mechanism in plants $[2,5,6]$. We also found that most stomata on tomato epidermal peels 168 remained closed after inoculation of a nonhost pathogen, $P$. syringae pv. tabaci (Fig. 1) The nonhost HR cell death at the site of infection is the most common defense 170 mechanism observed in many plants in response to nonhost bacterial pathogens (Mysore \& Ryu, 171 2004). Supplemental figure S1 shows that when nonhost pathogen $P$. syringae pv. tabaci was 172 infiltrated on tomato leaf, nonhost HR cell death was observed at the site of inoculation, while 173 host pathogen P. syringae pv. tomato DC3000 suppressed HR cell death (Fig. S1B). early plant defense responses including stomatal closure [2, 3]. We speculated that COR can suppress stomata closure induced by a nonhost pathogen and nonhost HR cell death-induced $P$. syringae pv. tabaci in tomato. In this study, we performed experiments to examine whether COR plays a role in inhibiting the early defense responses against nonhost pathogen $P$. syringae pv. 179 tabaci in tomato. 


\section{Coronatine inhibits stomatal closure induced by nonhost pathogen, $P$. syringae pv. tabaci}

184

185

186

187

188

189

190

191

192

193

194

195

196

197

198

199

200

201

202

203

204

205

Phytopathogens have evolved specific virulence factors to overcome early plant defense responses. In the case of virulent pathogen $P$. syringae pv. tomato strain DC3000, three hours after infection, bacteria produce the diffusible virulence factor coronatine (COR) in the apoplast and on the plant surface to reopen closed stomata, allowing increased bacterial entry (Melotto et al, 2008; Melotto et al, 2006; Underwood et al, 2007). However, most stomata remained closed in tomato when inoculated with a nonhost pathogen, $P$. syringae pv. tabaci (Fig. 1). To determine if COR can suppress the stomatal closure induced by a nonhost pathogen, we added COR (100 ng/ml) to $P$. syringae pv. tabaci suspension, and tomato epidermis was incubated with this suspension for three hours. Interestingly, most stomata remained open, and the aperture size of open stomata was similar to that of an aperture of stomata incubated with stomata opening buffer (Fig. 1). These findings indicate that COR acts as a virulence factor to disrupt stomatal closure induced by nonhost pathogen $P$. syringae pv. tabaci in tomato.

\section{Coronatine delays nonhost HR cell death induced by nonhost pathogen $P$. syringae pv.} tabaci

In addition to the COR-mediated inhibition of stomatal closure, we also examined whether COR can suppress nonhost HR cell death induced by $P$. syringae pv. tabaci. It has been known that COR is not a host-specific phytotoxin (Uppalapati et al, 2005), but it has never been reported whether COR can delay or suppress HR cell death in plants. As shown in Supplemental figure S1, the inoculation of $P$. syringae pv. tabaci induced typical nonhost HR cell death on tomato leaves within 24 hours after infiltration (hpi), while host pathogen P. syringae pv. tomato DC3000 did not induce any visible cell death at that time point. We speculate that the nonhost 
206 HR in tomato is triggered either by PAMPs or effectors of nonhost pathogen P. syringae pv. 207 tabaci. Such PAMP- and/or effector-triggered HR is probably suppressed during P. syringae pv. 208 tomato DC3000-tomato interaction.

209 Interestingly, nonhost HR cell death was not observed at 24 hpi when P. syringae pv. 210 tabaci was infiltrated along with COR in contrast to infiltration of $P$. syringae pv. tabaci alone 211 (Fig. 2A). At 48 hpi, even though the nonhost HR cell death was visible at both infiltration sites, 212 the cell death caused by infiltration of $P$. syringae pv. tabaci + COR was milder compared to $P$. 213 syringae pv. tabaci alone. This result clearly indicates that COR delays nonhost HR cell death 214 caused by a nonhost bacterial pathogen in tomato. However, the COR-mediated cell death 215 suppression is not strong enough to completely suppress the HR caused by a nonhost pathogen. 216 HR is associated with defenses that are manifested by development of rapid cell death through 217 the SA-mediated pathway (Alvarez, 2000; Mysore \& Ryu, 2004). It has been reported that COR 218 inhibit SA accumulation in Arabidopsis (Zheng et al, 2012). To investigate the role of SA in 219 delaying nonhost HR cell death, we examined nonhost HR cell death in ICS-silenced tomato 220 plants (ICS-RNAi; (Uppalapati et al, 2007). ICS is required for SA biosynthesis in plants. The 221 nonhost HR cell death was not detected 24 hours after infiltration of $P$. syringae pv. tabaci alone 222 or $P$. syringae pv. tabaci + COR. Mild HR was observed 48 hours after infiltration with $P$. 223 syringae pv. tabaci alone or P. syringae pv. tabaci + COR in ICS-RNAi and was much weaker 224 than the HR observed in non-silenced wild-type tomato plants. Interestingly, no difference was 225 found between infiltration of $P$. syringae pv. tabaci alone or with $P$. syringae pv. tabaci + COR 226 (Fig. 2A). This result suggests that the delay of nonhost HR by COR is likely due to suppression 227 of the SA pathway. 

pathogen, P. syringae pv. phaseolicola (Fig. 2B), suggesting that the COR response was not specific to a particular pathogen. In addition, we also show that $\mathrm{H}_{2} \mathrm{O}_{2}$ accumulation (by DAB staining), a typical response during HR, was suppressed by COR (Fig 2B). To further examine the delay of nonhost HR cell death by COR, we infiltrated $N$. benthamiana (a nonhost plant) with P. syringae pv. tomato DC3000 $\left(10^{3} \mathrm{CFU} / \mathrm{ml}\right)$ or P. syringae pv. tomato DB29 $\left(10^{3} \mathrm{CFU} / \mathrm{ml}\right)$, a mutant strain of DC3000 that does not produce COR (Uppalapati et al, 2007). After 24 hours of infiltration, the level of nonhost HR cell death by P. syringae pv. tomato DB29 was much higher than that of P. syringae pv. tomato DC3000 (Fig. 2C). This finding clearly indicates that COR is a nonhost-specific phytotoxin, and COR-producing $P$. syringae pathovars can delay nonhost HR cell death.

COR has been shown to promote compatible bacterial pathogen growth and develop disease symptoms in Arabidopsis and tomato (Melotto et al, 2006; Uppalapati et al, 2007; Zheng et al, 2012). Here we show that in tomato when COR was added to P. syringae pv. tabaci suspension prior to tomato leaf infiltration, it promoted the growth of nonhost pathogen (Fig. 2D). The level of bacterial growth of nonhost pathogen $P$. syringae pv. tabaci (with COR) was similar to the host pathogen $P$. syringae pv. tomato DC3000 1 day after inoculation (dpi), but the bacterial population of $P$. syringae pv. tabaci was reduced at $3 \mathrm{dpi}$, suggesting that COR is not sufficient by itself to completely suppress the defense mechanism(s) of nonhost disease resistance. Alternatively, it is also possible that COR may not be stable in planta after 24 hrs and therefore was not able to further promote the growth of nonhost bacteria beyond $1 \mathrm{dpi}$. 
251 indicates that $P$. syringae pv. tabaci produces unknown virulence factors to suppress

252 PAMP-triggered immunity (PTI) in tobacco plants that may be different from the molecular

253 mechanism of COR-dependent virulence. As shown in Figure 2, COR can suppress nonhost HR

254 cell death during initial phases of nonhost pathogen infection, but cell death eventually appeared

255 after 24 hpi (Fig. 2A and 2C). This indicates other factors involved in defense mechanism of

256 nonhost resistance are functionally regulated. It has been known that reactive oxygen species

257 (ROS) and nitric oxide (NO) are important for HR cell death induced upon incompatible

258 pathogen infection in plants. A number of defense genes are involved in the ROS and NO

259 signaling pathway (Jones and Dangl, 2006). Recently, it has been shown that ornithine

260 delta-aminotransferase ( $\delta O A T)$ and proline dehydrogenases (ProDH) are involved in ROS

261 production in mitochondria and regulate defense responses such as HR cell death against nonhost

262 pathogens (Senthil-kumar and Mysore, 2012). The peroxisomal enzyme glycolate oxidase (GOX)

263 has also been reported as an essential component of nonhost resistance. In Arabidopsis, GOX

264 functions independently from NADPH oxidase (Respiratory burst oxidase homolog) and is

265 involved in $\mathrm{H}_{2} \mathrm{O}_{2}$ accumulation and callose deposition in response to nonhost pathogen

266 inoculation (Rojas et al. 2012). It is not clear whether COR can disrupt nonhost resistance

267 responses mediated by $\delta O A T$, ProDH, and GOX.

Coronatine represses the expression of SA-related defense genes during nonhost resistance

271 In previous studies, it has been demonstrated that COR activates the expression of JA-inducible

272 genes and suppresses SA-mediated defenses in tomato (Ishiga et al, 2009; Uppalapati et al, 2005;

273 Uppalapati et al, 2007). To determine the expression profiles of SA- and JA-related genes upon 
274 inoculation with host or nonhost pathogens supplemented with COR, we inoculated tomato

275 leaves with host pathogen $P$. syringae pv. tomato T1 and nonhost pathogen $P$. syringae pv. tabaci

276 with or without COR. Expression profiles of SA-mediated signaling pathway genes, such as

277 PR1a (pathogenesis-related protein 1a), PR1b (pathogenesis-related protein 1b), PR2b

278 (pathogenesis-related protein 2b), and ICS1 (Isochorismate synthase 1), and JA-mediated

279 signaling pathway genes, such as LoxD (Lipoxygenase D) and OPR3 (12-Oxophytodienoic acid

280 reductase 3) were evaluated by real-time quantitative RT-PCR analysis at two time periods, 6 and

28112 hours post inoculation (hpi). Samples were not collected beyond $12 \mathrm{hpi}$, due to occurrence of

282 cell death. As shown in Fig. 3, the expression of SA-mediated signaling pathway genes,

283 including $P R 1 a, P R 1 b, P R 2$ and ICS1, was more strongly induced by nonhost pathogen $P$.

284 syringae pv. tabaci when compared to induction by host pathogen P. syringae pv. tomato T1. We

285 further tested if the addition of exogenous COR resulted in a suppression of SA-mediated

286 signaling pathway genes in P. syringae pv. tabaci-inoculated leaves. In COR-supplemented

287 leaves, the expression of $P R 1 a, P R 1 b, P R 2$ and ICS1 was significantly lower than nonhost

288 pathogen alone inoculated leaves. In contrast, the expression of the JA-inducible genes, such as

289 LoxD and OPR3, was more strongly induced in Psta-inoculated leaves supplied with COR when

290 compared to Psta or COR alone. These results strongly support the hypothesis that COR

291 functions to suppress the SA-mediated signaling pathway induction during nonhost disease

292 resistance. In addition, COR may exploit the endogenous antagonistic interactions between JA

293 and SA hormone signaling pathways, leading to inhibition of early plant defense mechanisms of

294 nonhost disease resistance.

295

296 


\section{Conclusion}

299

300

A number of studies have been reported regarding the role of COR in suppression of early plant

defense responses like stomatal closure and induction of SA. However, it was not clear if COR

can also suppress defense responses induced by nonhost pathogens. This study clearly

demonstrates that COR suppresses nonhost HR, stomatal closure induced by nonhost pathogens

and disrupts the hormonal defense signaling pathway activated during nonhost resistance.

However, COR is not sufficient by itself to completely suppress nonhost resistance. This

indicates that other downstream defense components are not targeted by COR during nonhost

resistance. It warrants further investigation to understand the molecular mechanism of COR for suppression of early plant defense responses during nonhost resistance.

\section{Figure Legend}

Figure 1. COR suppress stomatal closure induced by P. syringae pv. tabaci in tomato (A and B).

To determine suppression of stomatal closure by COR, tomato epidermal peels were floated on stomata opening buffer $(\mathrm{KCl} 30 \mathrm{mM})$ and stomata were observed under a light microscope to assure stomatal opening. The epidermal peels were incubated with $P$. syringae pv. tabaci suspension $\left(5 \times 10^{4} \mathrm{CFU} / \mathrm{ml}\right)$ with or without COR in the bacterial suspension $(100 \mathrm{ng} / \mathrm{ml})$ for

317 three hours. Images (A) were taken using a light microscope, and individual stomatal apertures

318 were measured (B) using ImageJ software (http://rsb.info.nih.gov/ij/). Approximately 50 stomata

319 were counted for each epidermal peel, and a total of three peels were used for the analysis of 
320

321

322

323

324

325

326

327

328

329

330

331

332

333

334

335

336

337

338

339

340

341

each treatment. Bars represent the means \pm standard deviation (SD) from two independent experiments. Different letters above bars indicate significantly different values $(\mathrm{P}<0.05$, Student's $t$ test).

Figure 2. COR delays nonhost HR cell death induced by P. syringae pv. tabaci and P. syringae pv. phaseolicola in tomato. (A) Wild-type and ICS-RNAi tomato leaves were infiltrated with $P$. syringae pv. tabaci $\left(6 \times 10^{2} \mathrm{CFU} / \mathrm{ml}\right)$ with or without COR $(100 \mathrm{ng} / \mathrm{ml})$. The development of nonhost HR cell death was determined 24 hours and 48 hours after infiltration. (B) Another nonhost pathogen, $P$. syringae pv. phaseolicola, $\left(6 \times 10^{2} \mathrm{CFU} / \mathrm{ml}\right)$ was syringe (needleless) infiltrated with or without COR (100 ng/ml) to tomato leaf. After 24 hours of infiltration, a photograph was taken (lower panel) and leaf samples were collected for DAB staining to visualize $\mathrm{H}_{2} \mathrm{O}_{2}$ production at the site of infection (upper panel). (C) Delay of nonhost HR cell death by COR producing nonhost pathogen P. syringae pv. tomato DC3000 in N. benthamiana. P. syringae pv. tomato DB29 is the mutant strain that does not produce COR. A photograph was taken 24 hours after infiltration. (D) The bacterial population of P. syringae pv. tomato DC3000 (Pst DC3000), P. syringae pv. tabaci (Pstab) and P. syringae pv. tabaci with COR (Pstab + COR) was measured zero, one and three days after syringe inoculation. The bacterial concentration of $2 \times 10^{2} \mathrm{CFU} / \mathrm{ml}$ was used for both pathogens. Bars represent the means \pm standard deviation (SD) from three leaf samples per treatment. Three independent experiments were performed. Different letters above bars indicate significantly different values $(\mathrm{P}<0.05$, Student's $t$ test). 
342 Figure 3. Expression profiles of SA- and JA-related defense genes in tomato leaves inoculated

343 with nonhost pathogen P. syringae pv. tabaci (Psta) and host pathogen P. syringae pv. tomato T1

344 (Pst T1), and COR. Tomato leaves were treated with distilled water (mock control), COR (100

$345 \mathrm{ng} / \mathrm{ml}$ ) or inoculated with Psta, Psta with COR or Pst T1. The expression of genes encoding

346 PR1a, PR1b, PR2b, ICS1, LoxD and OPR3 was evaluated by real-time quantitative RT-PCR.

347 Bars represent the means \pm standard deviation (SD) from three biological replications and three

348 technical replications per experiment. Different letters and symbols above bars indicate

349 significantly different values ( $\mathrm{P}<0.05$, Student's $t$ test).

350

\section{References}

Alvarez ME (2000) Salicylic acid in the machinery of hypersensitive cell death and disease resistance. Plant Molecular Biology 44: 429-442

Bender CL (1999) Chlorosis-inducing phytotoxins produced by Pseudomonas syringae. European J Plant Pathology 105: 1-12

357

358

359

360

Bender CL, Stone HE, Sims JJ, Cooksey DA (1987) Reduced pathogen fitness of Pseudomonas syringae pv. tomato Tn5 mutants defective in coronatine production. Physiol Mol Plant Pathol 30: $273-283$

Boller T, Felix G (2009) A renaissance of elicitors: perception of microbe-associated molecular patterns and danger signals by pattern-recognition receptors. Annu Rev Plant Biol 60: 379-406

Brooks DM, Bender CL, Kunkel BN (2005) The Pseudomonas syringae phytotoxin coronatine promotes virulence by overcoming salicylic acid-dependent defences in Arabidopsis thaliana. Mol Plant Pathol 6: 629-639

Brooks DM, Hernandez-Guzman G, Kloek AP, Alarcon-Chaidez F, Sreedharan A, Rangaswamy V, Penaloza-Vazquez A, Bender CL, Kunkel BN (2004) Identification and characterization of a well-defined series of coronatine biosynthetic mutants of Pseudomonas syringae pv. tomato DC3000. Mol Plant Microbe Interact 17: 162-174

Cui J, Bahrami AK, Pringle EG, Hernandez-Guzman G, Bender CL, Pierce NE, Ausubel FM (2005) Pseudomonas syringae manipulates systemic plant defenses against pathogens and herbivores. Proc Natl Acad Sci U S A 102: 1791-1796 
400

401

402

403

404

405

406

407

408

409

410

411

412

413

414

415

416

417

418

419

420

421

422

423

E. Mitchell R (1985) Coronatine biosynthesis: Incorporation of l-[U-14C]isoleucine and l-[U-14C] threonine into the 1-amido-1-carboxy-2-ethylcyclopropyl moiety. Phytochemistry 24: $247-249$

F. UT, Durbin RD (1980) Hydrolysis of tabtoxins by plant and bacterial enzymes. Experientia 36: $301-302$

Ishiga Y, Uppalapati SR, Ishiga T, Elavarthi S, Martin B, Bender CL (2009) The phytotoxin coronatine induces light-dependent reactive oxygen species in tomato seedlings. New Phytologist 181: $147-160$

Jones JD, Dangl JL (2006) The plant immune system. Nature 444: 323-329

Katsir L, Schilmiller AL, Staswick PE, He SY, Howe GA (2008) COI1 is a critical component of a receptor for jasmonate and the bacterial virulence factor coronatine. Proc Natl Acad Sci U S A 105: $7100-7105$

Melotto M, Underwood W, He SY (2008) Role of stomata in plant innate immunity and foliar bacterial diseases. Annu Rev Phytopathol 46: 101-122

Melotto M, Underwood W, Koczan J, Nomura K, He SY (2006) Plant stomata function in innate immunity against bacterial invasion. Cell 126: 969-980

Mysore KS, Ryu CM (2004) Nonhost resistance: how much do we know? Trends Plant Sci 9: 97-104

Preston GM, Bertrand N, Rainey PB (2001) Type III secretion in plant growth-promoting Pseudomonas fluorescens SBW25. Mol Microbiol 41: 999-1014

Rojas CM, Senthil-Kumar M, Wang K, Ryu C-M, Kaundal A, Mysore KS (2012) Glycolate Oxidase Modulates Reactive Oxygen Species-Mediated Signal Transduction during Nonhost Resistance in Nicotiana benthamiana and Arabidopsis. The Plant Cell 24: 336-352

Senthil-Kumar M, Mysore KS (2012) $\delta$-ornithine aminotransferase and proline dehydrogenase genes play a role in nonhost disease resistance by regulating pyrroline-5-carboxylate metabolism-induced hypersensitive response. Plant Cell \& Environment 35: 1329-1343.

Underwood W, Melotto M, He SY (2007) Role of plant stomata in bacterial invasion. Cell Microbiol 9: 1621-1629

Uppalapati SR, Ayoubi P, Weng H, Palmer DA, Mitchell RE, Jones W, Bender CL (2005) The phytotoxin coronatine and methyl jasmonate impact multiple phytohormone pathways in tomato. Plant J 42: 201-217

Uppalapati SR, Ishiga Y, Wangdi T, Kunkel BN, Anand A, Mysore KS, Bender CL (2007) The phytotoxin coronatine contributes to pathogen fitness and is required for suppression of salicylic 
424 acid accumulation in tomato inoculated with Pseudomonas syringae pv. tomato DC3000. Mol 425 Plant Microbe Interact 20: 955-965

Weiler EW, Kutchan TM, Gorba T, Brodschelm W, Niesel U, Bublitz F (1994) The Pseudomonas

428 phytotoxin coronatine mimics octadecanoid signalling molecules of higher plants. FEBS Lett 429 345: 9-13

430

431 Zhao Y, Thilmony R, Bender CL, Schaller A, He SY, Howe GA (2003) Virulence systems of 432 Pseudomonas syringae pv. tomato promote bacterial speck disease in tomato by targeting the 433 jasmonate signaling pathway. Plant J 36: 485-499

434

435 Zheng X-y, Spivey Natalie W, Zeng W, Liu P-P, Fu Zheng Q, Klessig Daniel F, He Sheng Y, 436 Dong X (2012) Coronatine Promotes Pseudomonas syringae Virulence in Plants by Activating a 437 Signaling Cascade that Inhibits Salicylic Acid Accumulation. Cell host \& microbe 11: 587-596

438

439

440

441 


\section{Figure 1}

Figure 1



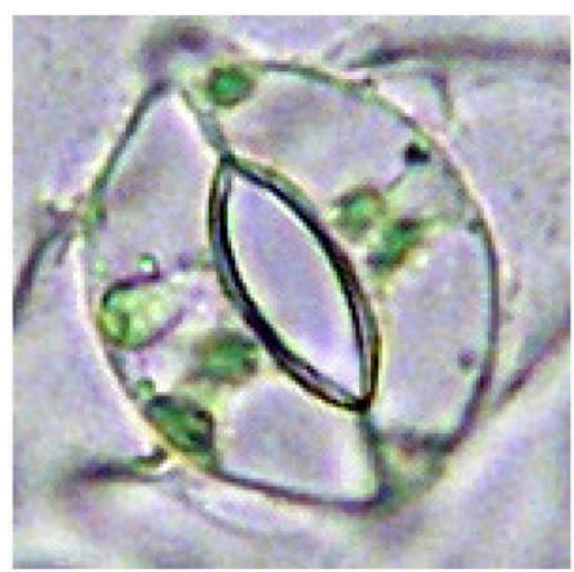

Stomata opening buffer

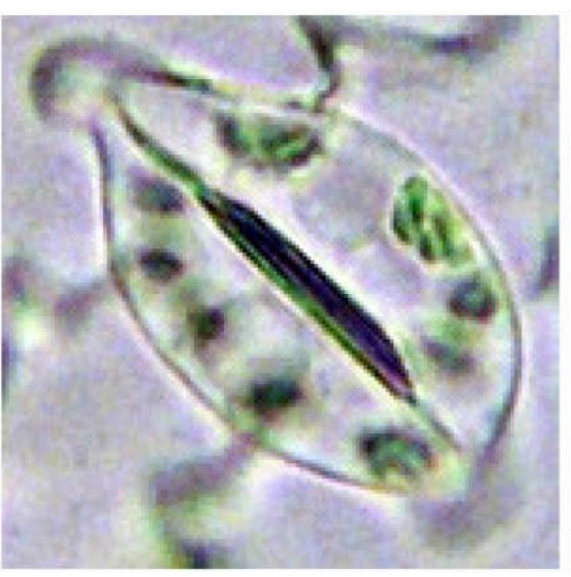

Pstab

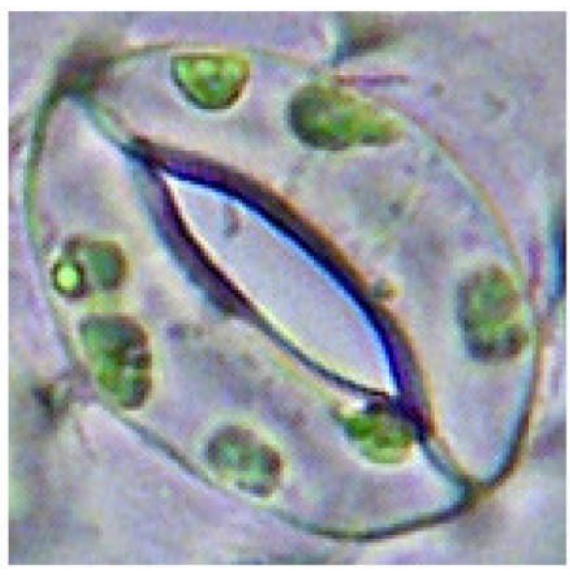

Pstab + COR

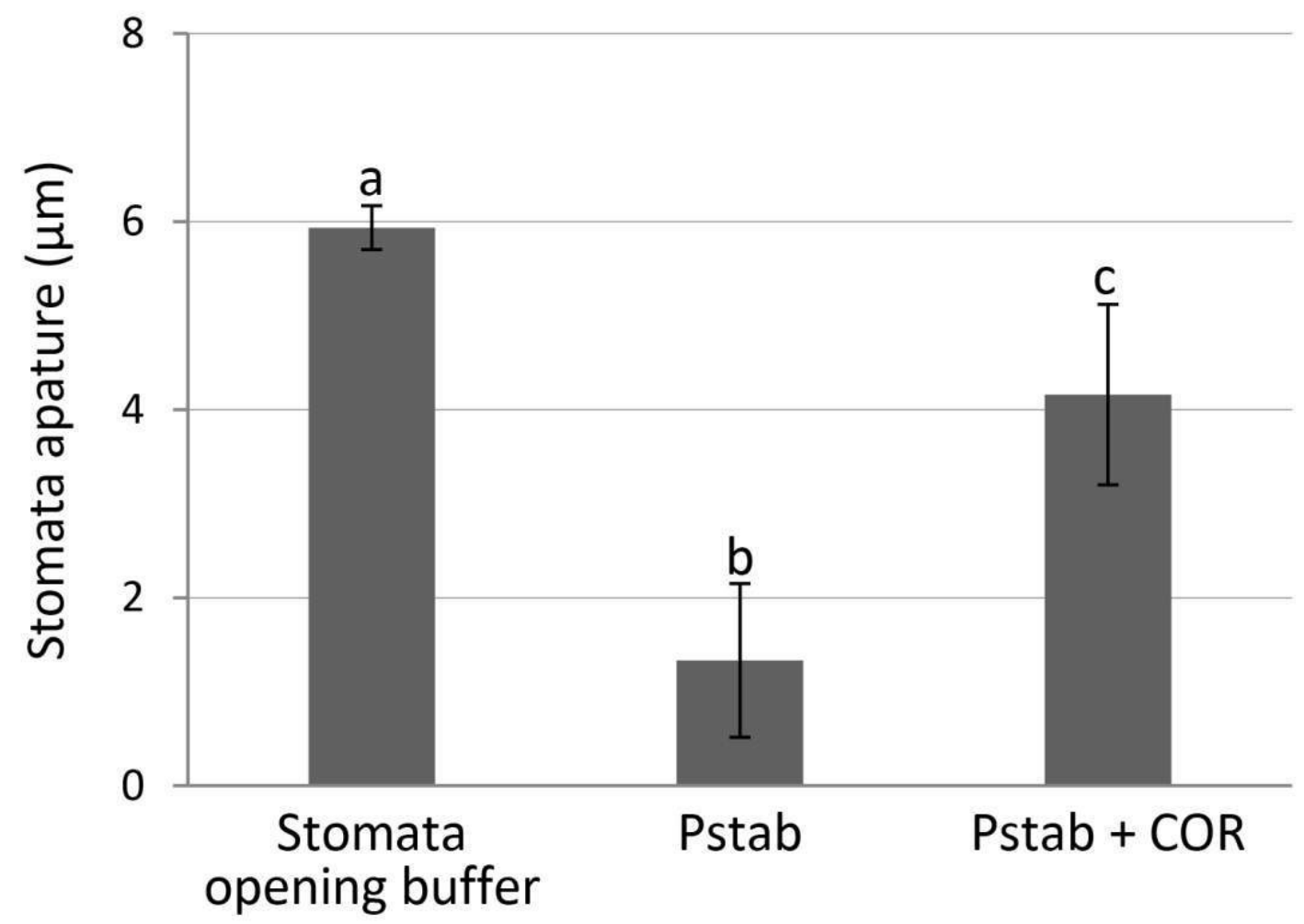


Figure 2

Figure 2 

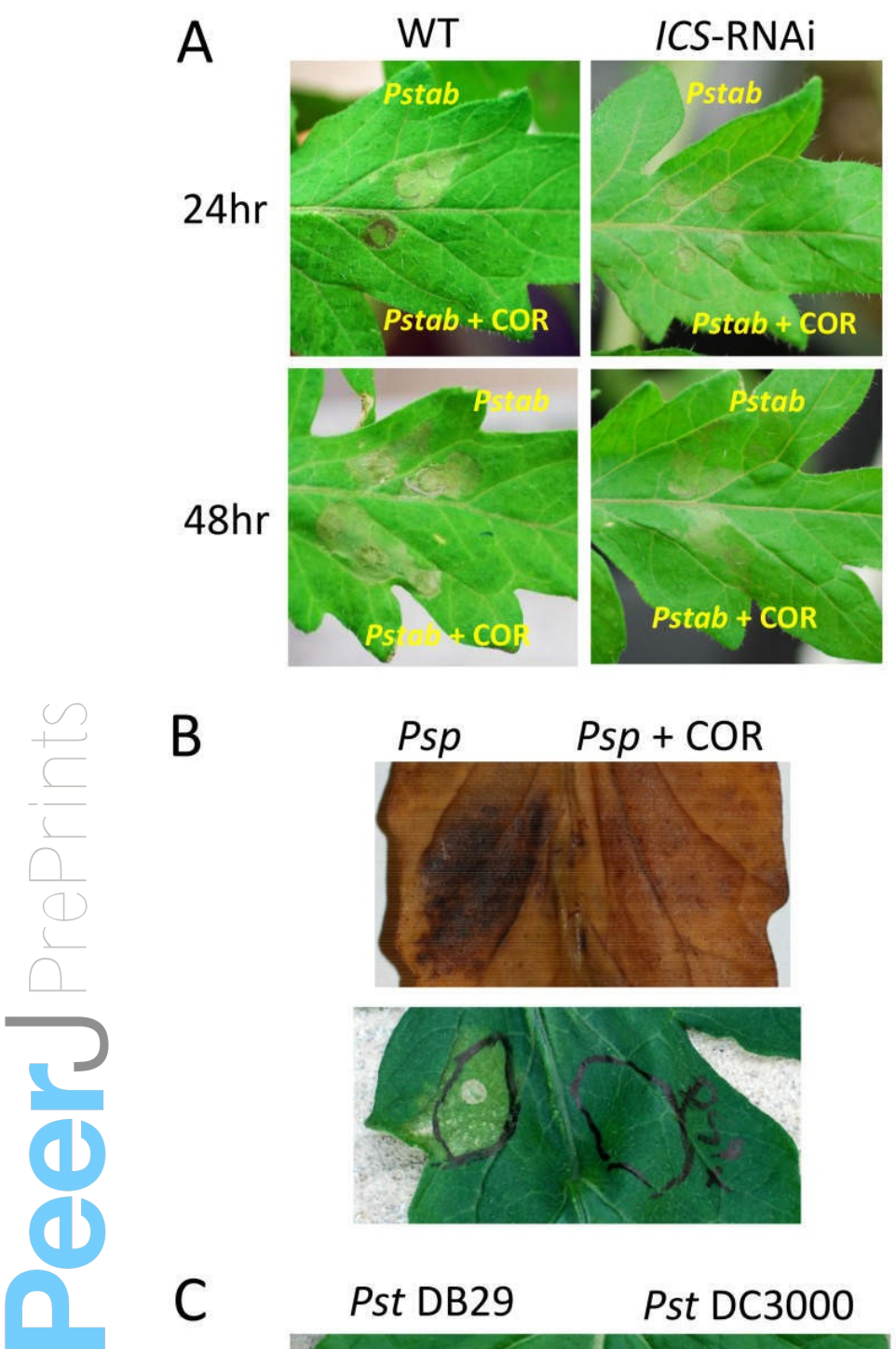

B
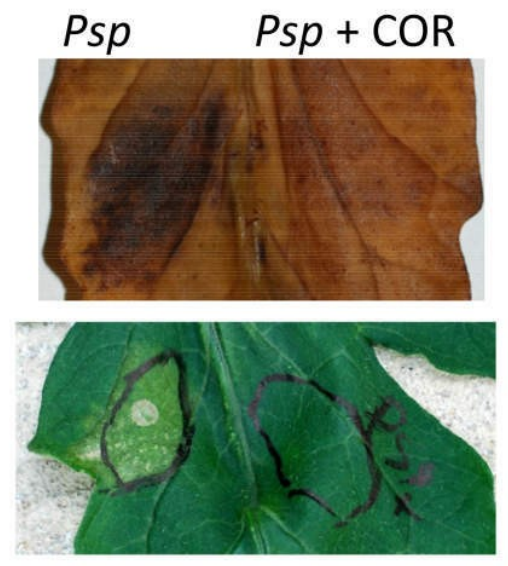

C

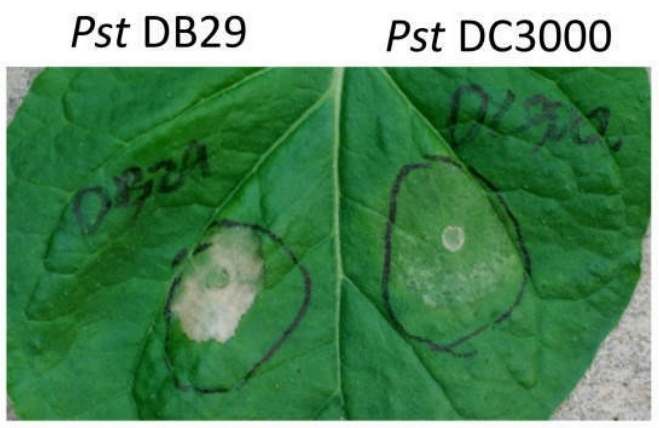

D

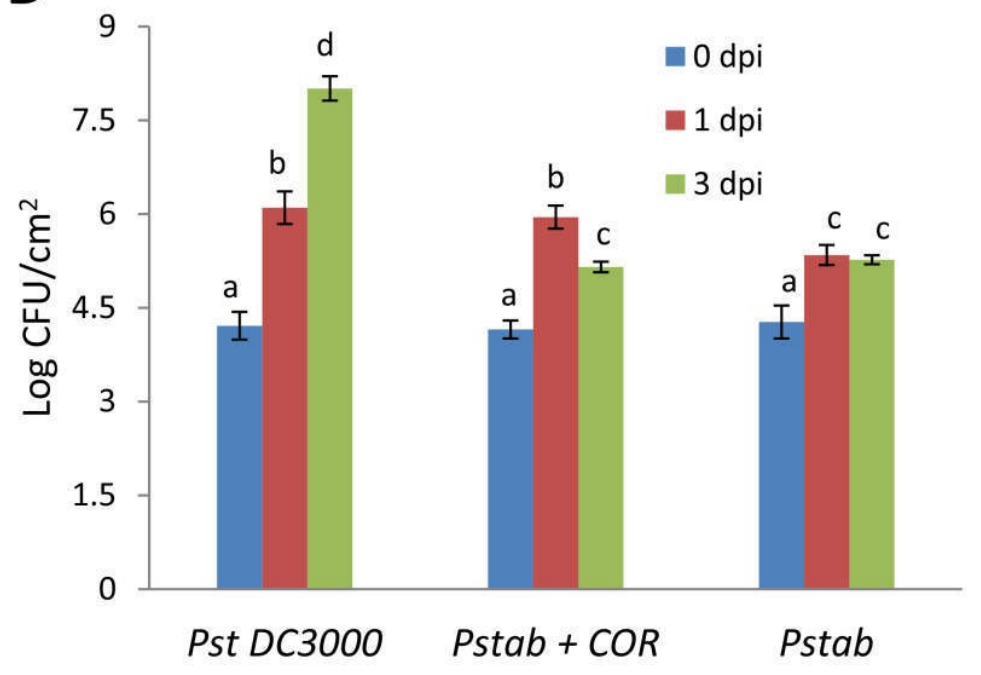


Figure 3

Figure 3 

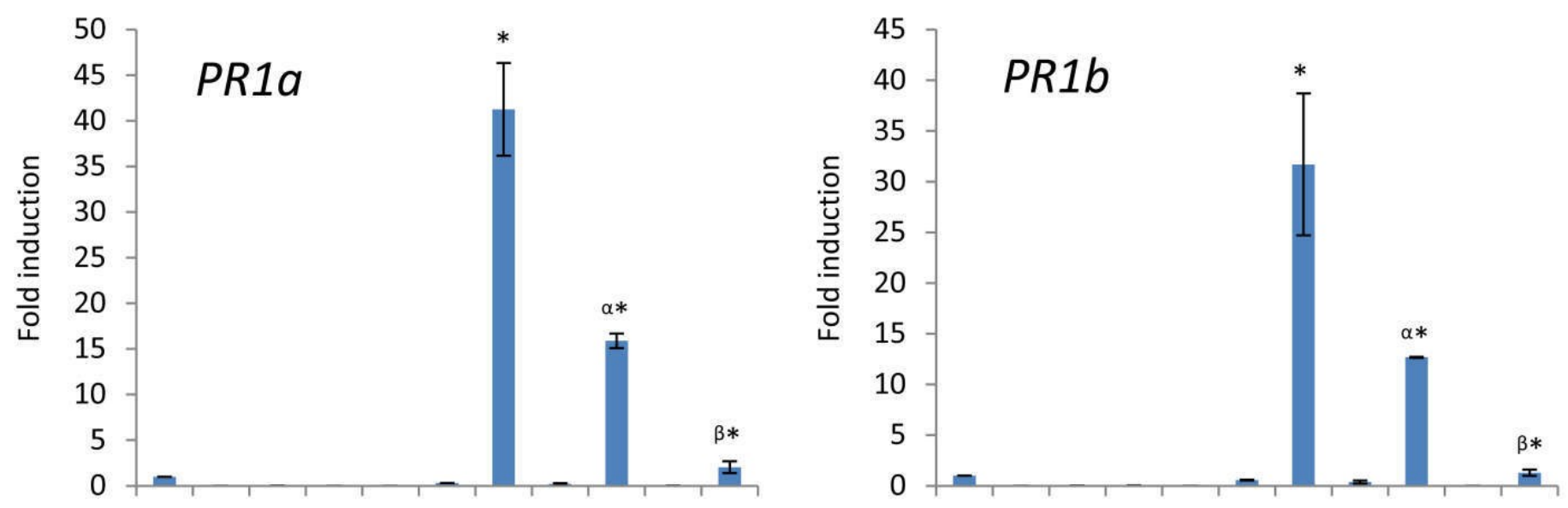

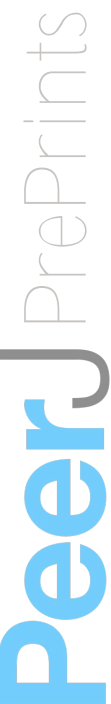
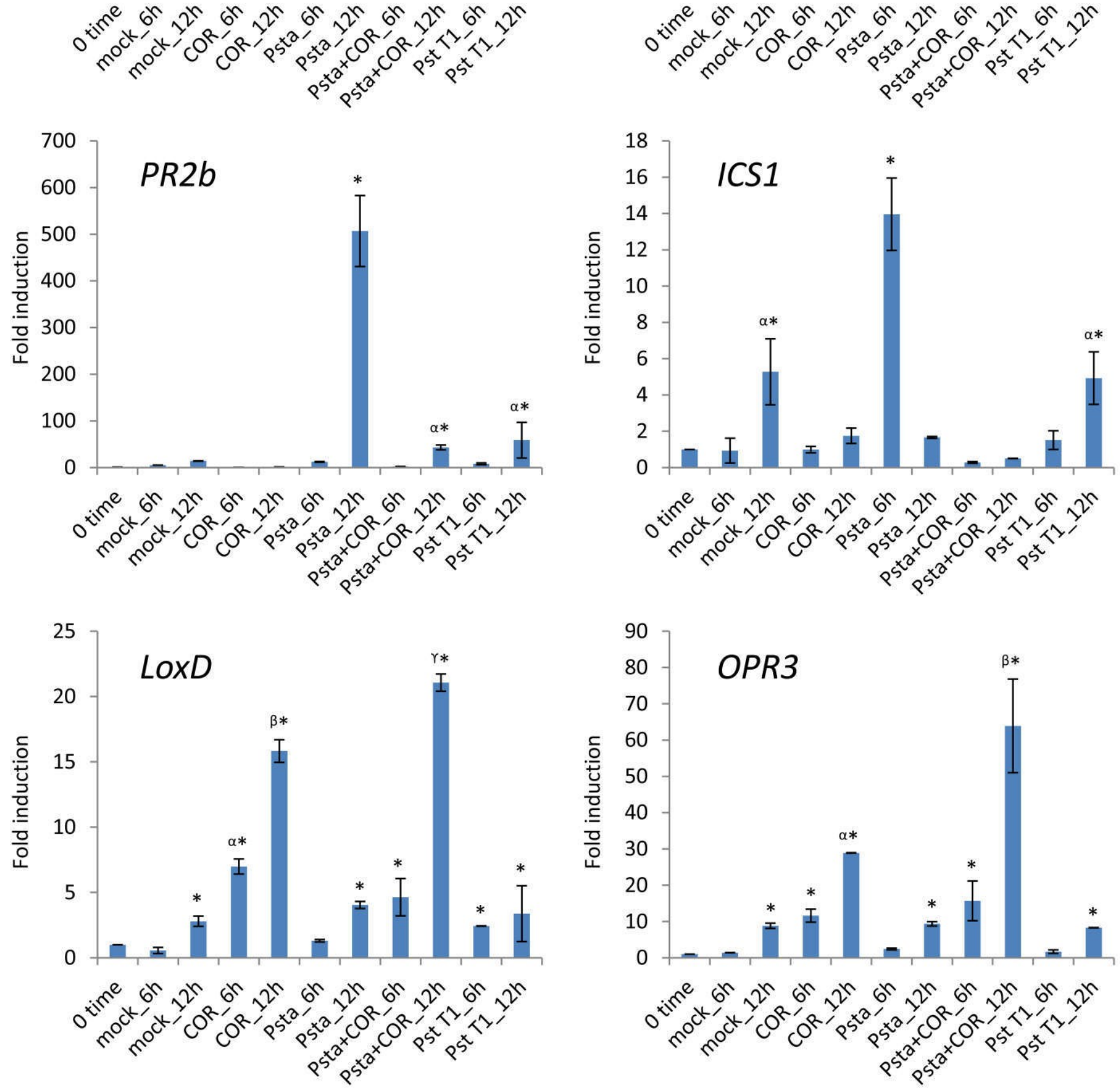